\title{
Sizing a rainwater harvesting cistern by minimizing costs
}

\author{
Norman Pelak ${ }^{\mathrm{a}, *}$, Amilcare Porporato ${ }^{\mathrm{a}, \mathrm{b}}$ \\ ${ }^{a}$ Duke University, Department of Civil and Environmental Engineering, Room 121 Hudson \\ Hall, Box 90287, Durham, NC 27708, USA \\ ${ }^{b}$ Duke University, Nicholas School of the Environment, Environment Hall, 9 Circuit Drive, \\ Box 90328, Durham, NC 27708, USA
}

\begin{abstract}
Rainwater harvesting (RWH) has the potential to reduce water-related costs by providing an alternate source of water, in addition to relieving pressure on public water sources and reducing stormwater runoff. Existing methods for determining the optimal size of the cistern component of a RWH system have various drawbacks, such as specificity to a particular region, dependence on numerical optimization, and/or failure to consider the costs of the system. In this paper a formulation is developed for the optimal cistern volume which incorporates the fixed and distributed costs of a RWH system while also taking into account the random nature of the depth and timing of rainfall, with a focus on RWH to supply domestic, nonpotable uses. With rainfall inputs modeled as a marked Poisson process, and by comparing the costs associated with building a cistern with the costs of externally supplied water, an expression for the optimal cistern volume is found which minimizes the water-related costs. The volume is a function of the roof area, water use rate, climate parameters, and costs of the cistern and of the external water source. This analytically tractable expression makes clear the dependence of the optimal volume on the input parameters. An analysis of the rainfall partitioning also characterizes the efficiency of a particular RWH system configuration and its potential for runoff reduction. The results are compared to the RWH system at the Duke Smart Home in
\end{abstract}

${ }^{*}$ Corresponding author

Preprint submitted to Journal of Hydrology

August 11, 2016

(C) 2016. This manuscript version is made available under the Elsevier user license http://www.elsevier.com/open-access/userlicense/1.0/ 


\begin{tabular}{lll} 
Symbol & Units & Parameter Name \\
\hline$A$ & $\mathrm{~m}^{2}$ & Roof Area \\
$c$ & - & Normalized Storage Volume \\
$D_{c}$ & - & Cistern Demand Index \\
$G$ & $\$$ & Total Cost \\
$G_{d}$ & $\$$ & Distributed Costs \\
$G_{f}$ & $\$$ & Fixed Costs \\
$h$ & $\mathrm{~m}^{3} \mathrm{~d}^{-1}$ & Constant Water Demand Rate \\
$H$ & $\mathrm{~m}^{3} \mathrm{~d}^{-1}$ & Water Demand Rate (from Cistern) \\
$H_{m}$ & $\mathrm{~m}^{3} \mathrm{~d}^{-1}$ & Water Demand Rate (from Municipal Source) \\
$p_{0}$ & - & Probability that $c=0$ \\
$Q$ & $\frac{m^{3}}{d}$ & Overflow Rate \\
$q$ & $\frac{\$}{m^{3}}$ & Storage Capacity Unit Cost \\
$R$ & $\frac{m}{d}$ & Rainfall Rate \\
$R W H$ & - & Rainwater Harvesting \\
$r$ & $\frac{\$}{m^{3}}$ & Water Unit Cost \\
$S H$ & - & Smart Home \\
$T$ & $\mathrm{~d}$ & Lifetime of Cistern \\
$V$ & $\mathrm{~m}^{3}$ & Cistern Volume \\
$\alpha$ & $\mathrm{mm}^{3}$ & Mean Rainfall Event Depth \\
$\phi$ & - & Runoff Coefficient \\
$\gamma$ & - & Dimensionless Cistern Volume \\
$\Theta$ & $\mathrm{d}^{-1}$ & Mean Rainfall Event Frequency \\
$\Theta$ & - & Heaviside Step Function \\
\hline & & \\
\hline & & \\
\hline & &
\end{tabular}

Table 1: A guide to the symbols and abbreviations used in this paper.

Durham, NC, USA to show how the method could be used in practice.

Keywords: rainwater harvesting, optimal size, cost minimization, sustainable water use 


\section{Introduction}

In a period of rapidly rising populations and climate uncertainty, rainwater harvesting $(\mathrm{RWH})$ is seen as an increasingly attractive option to reduce the pressure on diminishing water supplies in many regions of the world (Pandey et al., 2003). Its potential for runoff reduction also has benefits even in areas where water is relatively abundant (Steffen et al., 2013, Sample and Liu, 2014 Walsh et al., 2014, Wang and Zimmerman, 2015). When used as an alternative water supply, captured rainwater may be used in nonpotable applications such as agriculture, car washing, and toilet flushing. Less commonly due to the cost of treatment, it may be used as a potable water source. In this paper we focus on designing RWH systems for domestic, nonpotable uses with a relatively constant demand, thereby avoiding complications such as the dependence of agricultural demand on soil moisture levels and the additional cost and complexity of incorporating a water treatment system.

The volume of the storage tank or cistern is perhaps the most important aspect in the design of a RWH system, but the methods to determine this volume have various drawbacks. Basic methods which could be applied by anyone exist (Ball, 2001; Krishna et al., 2005, Jones and Hunt, 2008) and may be as simple as sizing the cistern based on a fraction of the total average annual rainfall, but this approach ignores much of the information that could be obtained to better inform the design. Numerous methods of a more technical nature have been employed to study this question, focusing to a large degree on design criteria related to reliability, which is generally defined as the percentage of time that the RWH system was able to meet the desired demand (e.g., Basinger et al. (2010)). Reliability is naturally of concern in the design of any RWH system, and is likely to be the dominant one in situations where it is the primary or the only water source. However, other water sources (such as municipal supplies or water trucks) may be available, each with an associated cost. Considering these sources in the design process allows for a more complete picture of the utility and benefits of the system. Economic considerations must also be examined, as the 
appeal of RWH will be limited if it is not cost-effective. Government regulations encouraging or mandating such systems also provide a political dimension which could increase their attractiveness.

■ Many previous studies (e.g. Lee et al. (2000); Ghisi et al. (2007); Cowden et al. (2008); Basinger et al. (2010); Jones and Hunt (2010); Khastagir and Jayasuriya (2010); Steffen et al. (2013); Fernandes et al. (2015)) utilized numerical approaches to study optimal cistern design. Some, including Lee et al. (2000), Ghisi et al. (2007), Khastagir and Jayasuriya (2010), and Steffen et al. (2013), developed regression equations which are simple to use, but dependent on numerical data and thus highly specific to certain areas. These investigations also often had applications to particular regions or cities (Lee et al., 2000, Ghisi et al. 2007, Guo and Baetz, 2007; Cowden et al., 2008; Abdulla and Al-Shareef, 2009 Basinger et al., 2010, Jones and Hunt, 2010, Khastagir and Jayasuriya, 2010 Palla et al., 2012, Assayed et al., 2013, Mehrabadi et al., 2013; Steffen et al. 2013: Hanson and Vogel, 2014: Wang and Zimmerman, 2015, Rostad et al. 2016 ) and typically used available local rainfall records to optimize their designs. The drawbacks of relying too heavily on specific rainfall observations are that rainfall records are insufficient to capture the true variability, and moreover the results may not hold in other regions. Climate change is likely to increase the variability in rainfall patterns and amounts in the future (Easterling et al. 2000 Feng et al. 2013), adding further uncertainty and necessitating methods which can account for such changes, such as synthetic analytical representations of rainfall.

Here we develop an analytical expression for the optimal cistern size of a RWH system based on economic considerations. We use a parametric description of rainfall, in which rainfall occurs as a marked Poisson process (e.g., Rodríguez-Iturbe and Porporato, 2004). This simple representation of rainfall is parsimonious, mathematically tractable, and may be easily adapted to future climate scenarios with different rainfall patterns by adjusting the climate parameters. In areas where rainfall cannot be modeled exponentially, seasonal variation in rainfall could be incorporated by employing a time-dependent Pois- 
son process, a route which will be explored in future contributions. A similar approach, which also took into account the length of individual storm events, was used by Guo and Baetz (2007) to derive an analytic expression for optimal cistern size. However, as with most of the studies discussed previously, it focused on optimizing the cistern volume to obtain a desired reliability. Here we provide an expression that optimizes the cistern volume by minimizing the total cost, and make an application of the results to the Duke Smart Home in Durham, NC.

Minimizing total cost to find the optimal cistern storage volume has been used by several other authors. Okoye et al. (2015) used linear programming methods to minimize an objective cost function. Other studies used nonlinear programming methods to explore the tradeoffs between maximizing rainwater capture and reducing or delaying runoff (Sample and Liu, 2014), to design water networks for RWH in residential developments (Bocanegra-Martínez et al., 2014) and for water capture-reuse systems in a housing complex García-Montoya et al. 2015). These latter two studies had the dual goals of minimizing freshwater consumption and total cost. Walsh et al. (2014) examined the interesting case of a RWH system which was operated with the primary goal of runoff reduction. Liaw and Tsai (2004) developed curves by which an optimal cistern size could be selected which met a given reliability level and also minimized a cost function. Campisano and Modica (2012) used historical rainfall data to simulate the water balance in the cistern, developed empirical equations to describe the water savings efficiency in terms of dimensionless parameters, and combined these with a cost function which was then minimized. In contrast, our analysis is not dependent on historical rainfall data or simulations and is backed by mathematical models which have been widely applied to hydrological problems (see Section 2).

We also note that DeBusk et al. (2013) examined four existing RWH systems in North Carolina and found that they were not cost-effective over their expected lifetimes, but it is not clear that these systems were operated or sized in such a way as to minimize the owner's water-related costs. Our goal here is to assess 
the conditions of optimal cistern size as a function of rainfall regime as well as fixed and distributed costs under ideal operating conditions to provide a benchmark for further study and analysis of the impact of pricing policies and sustainability incentives on water consumption.

In the following sections, we will first describe the water balance in the cistern and formulate the problem in mathematical terms. Then, general solutions to related problems obtained by other researchers will be shown, along with the partitioning of the water balance. Finally, we will develop a cost function for the cistern over its lifetime and find an exact expression for the cistern volume which minimizes the total cost.

\section{Stochastic Water Balance in Cisterns}

The mass balance of water in a cistern which is filled by means of rooftop rainwater harvesting is as follows

$$
V \frac{d c}{d t}=\phi A R(t ; \alpha, \lambda)-H(c)-Q(c)
$$

where $V\left[\mathrm{~m}^{3}\right]$ is the cistern volume, $c$ is the normalized cistern storage volume ranging from zero to one, $\phi$ is a runoff coefficient, $A\left[\mathrm{~m}^{2}\right]$ is the area of the roof capable of collecting water, $R\left[\frac{m}{d}\right]$ is the stochastic rainfall rate with mean event depth $\alpha[m]$ and mean inter-arrival time $\frac{1}{\lambda}[d], H\left[\frac{m^{3}}{d}\right]$ is the rate of demand of water from the cistern, and $Q\left[\frac{\mathrm{m}^{3}}{d}\right]$ is the loss rate due to overflow. Here we assume that the cistern is covered, so that losses to evapotranspiration can be neglected, and that there are no losses to leakage. In using a runoff coefficient, we are essentially adapting the rational method (Farreny et al., 2011). The coefficient $\phi$ depends on factors such as the roof material and slope as well as the efficiency of the water collection system. A review by Farreny et al. (2011) found that they can range from 0.7 to 0.95 , but the value may be much lower for green roofs (Fassman-Beck et al. 2015). The latter two references contain tables which can assist in the selection of the proper runoff coefficient for different roof properties. As it does not qualitatively affect the results, we do not include the 
diversion of the first flush of rainfall events from the cistern, which is found in many RWH systems. However, first flush diversion can be incorporated using the censoring approach found in Rodríguez-Iturbe and Porporato (2004). We use the following form for the loss rate

$$
H(c)=\left\{\begin{array}{lll}
0 & \text { if } & c=0 \\
h & \text { if } & c>0
\end{array}\right.
$$

where $h$ is the constant rate of water demand. When $c=0$, water is assumed to be provided by another source, such as a municipal supply. The rate of losses due to overflow take the form

$$
Q(c)=(\phi R A-V(1-c)) \cdot \Theta(\phi R A-V(1-c)),
$$

where $\Theta$ is the Heaviside step function (Abramowitz and Stegun, 1972), defined here such that $\Theta$ (and thus $Q$ ) is equal to 0 unless a rainfall event causes $c$ to be greater than 1 . We assume that the RWH system is equipped with an adequately sized overflow pipe which allows the overflow to enter into the property's external storm sewer system. Sizing guidelines for such a pipe can be found in local plumbing and building codes, and typically require the pipe to be sized to handle a design storm rate of a particular duration and return period. In North Carolina, for example, if the overflow pipe must be sized for the 100 year, 1-hour storm (Jones and Hunt, 2008).

Equation (1) is similar to the minimalistic model for soil moisture balance developed by Milly (1993) and Porporato et al. (2004) (see also Porporato et al. (2002) and Rodríguez-Iturbe and Porporato (2004)). The underlying mathematical process is the Takacs process with an upper bound (Cox and Miller. 1977). The main results are presented below, but more details can be found in the Appendix.

\section{Non-dimensional parameters}

The system can be described by four variables $\left(\alpha, \lambda, \frac{V}{\phi A}\right.$, and $\left.\frac{h}{V}\right)$ which contain two base units ( $\mathrm{L}$ and T). Applying the Buckingham-Pi Theorem (Logan, 
2013 ) results in two dimensionless groups, for which we choose

$$
\gamma=\frac{V}{\phi A \alpha}
$$

146

and

$$
D_{c}=\frac{h}{\phi A\langle R\rangle},
$$

where $\langle R\rangle=\lambda \alpha$ is the mean rainfall rate. The brackets $\langle\cdot\rangle$ here and in the following analysis denote the ensemble average of a random variable.

We define $\gamma$ as the dimensionless cistern volume and $D_{c}$ as the cistern demand index. $\gamma$ characterizes the cistern volume, $V$, in relation to the volume which enters it in an average event, $\phi A \alpha . D_{c}$ is the ratio of the maximum water demand rate, $h$, to the rate at which rainfall can be captured, $\phi A\langle R\rangle$.

n Non-dimensional parameters were also used by Palla et al. (2011) and Campisano and Modica (2012) to characterize RWH systems. The two parameters chosen in the former study were the ratio of the cistern storage volume to the annual water supply (storage fraction) and the ratio of the annual water demand to the annual water supply (demand fraction), while the latter study had a modified storage fraction. The parameter $\gamma$ can be transformed to the storage fraction by dividing it by the number of rainfall events per year, $\lambda T$, where $T=365$ days. The demand fraction is similar to the cistern demand index, except that the former considers total losses to total supply over a year while the latter considers the corresponding rates. While both formulations provide similar information, we use (4) and (5) as they are not tied to a particular timeframe.

\subsection{Steady-State Solutions}

Because the losses are constant as long as $c \neq 0$, there is an atom of probability, $p_{0}$, that the cistern will be empty $(c=0)$. The steady-state solutions for the probability density function (PDF) and the atom of probability were obtained (Milly, 1993; Rodríguez-Iturbe and Porporato, 2004) (see Appendix) as

$$
p(c)=\frac{\gamma}{D_{c}} p_{0} e^{\gamma\left(\frac{1}{D_{c}}-1\right) c},
$$




$$
p_{0}=\frac{1-D_{c}}{e^{\gamma\left(\frac{1}{D_{c}}-1\right)}-D_{c}}
$$

172 Figure 1 shows the analytical PDF (right axes) and atom solutions (left axes), 173 along with sample time series for each case. For the special case of $D_{c}=1$, the 174 PDF and atom are given by

175

$$
p(c)=\frac{\gamma}{1+\gamma}
$$

$$
p_{0}=\frac{1}{1+\gamma}
$$

We note that the atom of probability in Equations $(7)$ and $(9)$ are dependent on $V$ through $\gamma$.

\section{Harvested Water Partitioning}

The amount of water captured, $\phi A\langle R\rangle$, is either consumed by the demand or lost to overflow. The long-term water balance in the cistern can therefore be partitioned as follows:

$$
\phi A\langle R\rangle=\langle H\rangle+\langle Q\rangle,
$$

or

$$
1=\frac{\langle H\rangle}{\phi A\langle R\rangle}+\frac{\langle Q\rangle}{\phi A\langle R\rangle},
$$

where $\langle H\rangle$ is the expected loss rate due to water demand that is supplied by the cistern and $\langle Q\rangle$ is the expected loss rate due to overflow. The expected loss rate $\langle H\rangle$ is equal to the constant loss rate $h$ times the fraction of time that the cistern is full

$$
\langle H\rangle=h\left(1-p_{0}\right),
$$

where $1-p_{0}$ is the fraction of time that the cistern is not empty.

We can express the non-dimensionalized partitioning of harvested water by dividing Equation 12 by the expected rate at which rainfall can be captured

$$
\frac{\langle H\rangle}{\phi A\langle R\rangle}=D_{c}\left(1-p_{0}\right) .
$$





Figure 1: Two PDFs with different cistern storage volumes and a roof with $A=267 \mathrm{~m}^{2}$, the approximate roof area of the Duke Smart Home in Durham, NC, USA (top plot), and a roof with half this area, $A=133.5 \mathrm{~m}^{2}$ (bottom plot), in order to show different possible shapes of the PDF. Gray lines correspond to a cistern volume of $7.95 \mathrm{~m}^{3}$ (the volume of the indoor cisterns at the Smart Home) and black lines correspond to a cistern volume of $19.2 \mathrm{~m}^{3}$ (the combined volume of the indoor and outdoor cisterns at the Smart Home). Other parameters are as in Table2 The inset plots contain sample time series for each combination of roof area and cistern volume. 


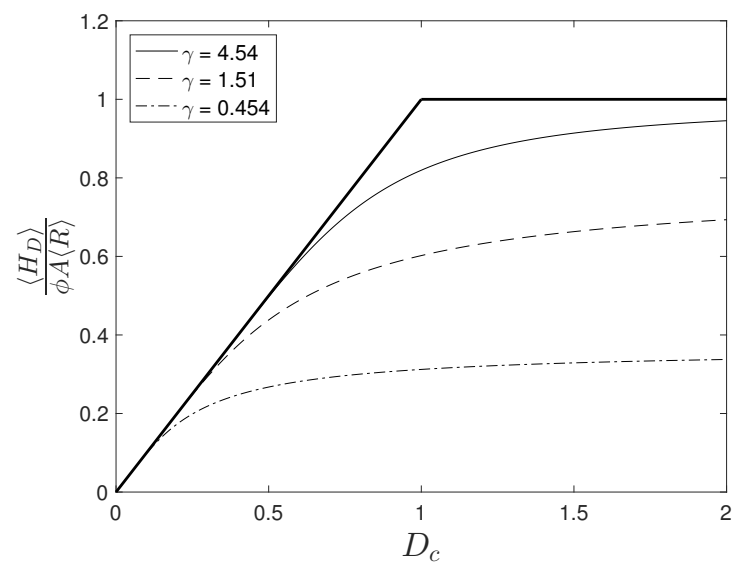

Figure 2: The ratio of water demand to rainfall rate as a function of the cistern demand index, $D_{c}$, for different values of $\gamma \cdot \gamma \approx 4.54$ for the Duke Smart Home, and other values which are $\frac{1}{3}$ and $\frac{1}{10}$ of the $\mathrm{SH}$ value were chosen to illustrate different possible shapes of the curve.

In this expression, $D_{c}$ is analogous to the Budyko dryness index (Budyko, 1974), which gives the ratio of the mean potential evapotranspiration to the mean rainfall rate. The comparison to the Budyko dryness index allows us to assess the efficiency of a particular RWH system configuration. For any location where climatic data and information about water use rates are available, we can quantify the potential for RWH to reduce the demand on local water sources. In the cistern partitioning curve, when $D_{c}<1$ it is not the available energy which prevents all of the water from being consumed by the demand but rather the available storage capacity. When $D_{c}>1$, however, the available water is the limit as in the original Budyko diagram. The expected use rate of water in the cistern comes closer to the maximum possible rate for larger values of the dimensionless cistern volume $\gamma$, as can be seen in Figure2, which plots the ratio of the water demand over the rainfall rate vs. the cistern demand index.

\section{Optimal Cistern Size}

Here we derive an expression for determining the optimal size of a cistern based on cost minimization. We consider a typical building, for which the total 


\begin{tabular}{llll} 
Parameter & Symbol & Units & Value \\
\hline Roof Area & $A$ & $\mathrm{~m}^{2}$ & 267 \\
Water Demand & $h$ & $\mathrm{~m}^{3} \mathrm{~d}^{-1}$ & 0.3 \\
Estimated Lifetime of Cistern & $T$ & $\mathrm{~d}$ & 10950 \\
Cistern Volume (Indoor Use) & $V$ & $\mathrm{~m}^{3}$ & 7.95 \\
Mean Rainfall Event Depth & $\alpha$ & $\mathrm{mm}$ & 8.2 \\
Runoff Coefficient & $\phi$ & - & 0.8 \\
Mean Rainfall Event Frequency & $\lambda$ & $\mathrm{d}^{-1}$ & 0.31 \\
\hline
\end{tabular}

Table 2: Parameters used in figures for the Duke Smart Home (SH) and Durham, NC, USA rainfall data. The cistern volume was obtained from the SH website (http://smarthome.duke.edu/) and the roof area from SH engineering plans. Water demand is for toilet flushing only, and is based on $6 \mathrm{~L} /$ flush for 10 residents flushing 5 times per day (http://www.home-water-works.org/indoor-use/toilets). Rainfall data for Durham, NC was obtained from Daly and Porporato (2006).

cost of a RWH system, $G[\$]$, is comprised of two parts: the initial or fixed cost of building and maintaining the cistern, $G_{f}[\$]$, and the distributed cost, $G_{d}[\$]$, of supplying the water from an external source when there is an insufficient volume of water in the cistern to meet the demand. Below we will examine particular forms for each, and apply these forms to the Duke Smart Home in Durham, NC, for which the parameters can be found in Table 2.

\subsection{Fixed Costs}

We can reasonably assume that the cost of building and maintaining a cistern will increase with its volume $V$. We do not explicitly consider maintenance costs, but by assuming either that they are independent of the cistern size or that they scale with cistern volume in the same way as do the building costs, they can easily be incorporated. Figure 3 plots commercial cistern prices against storage capacity for above-ground plastic cisterns and suggests that a linear relationship is reasonable, although it is possible that an economy-of-scale effect produces a nonlinear relationship for larger cistern volumes. A similar relationship was used by Campisano and Modica (2012) and can also be found in Table 3 of 


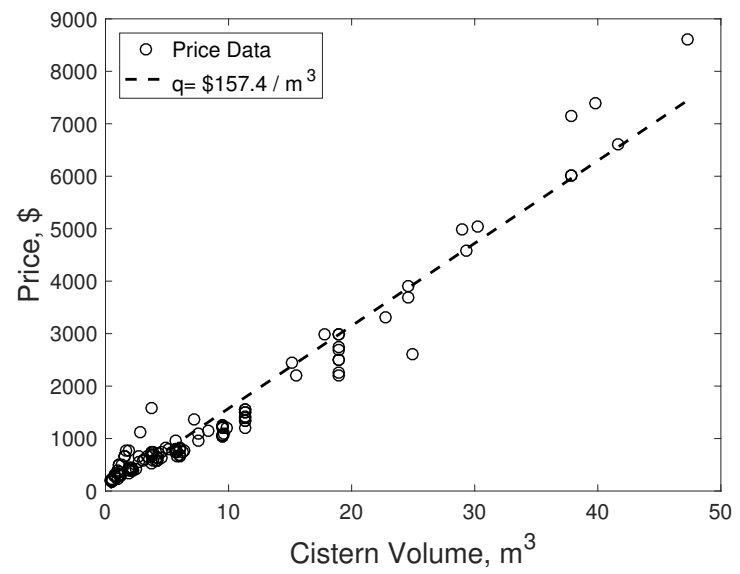

Figure 3: Cost $[\$]$ vs. cistern volume $\left[\mathrm{m}^{3}\right]$ for commercially available cisterns. Data are for a variety of manufacturers and were taken from www.rainharvest.com. We note that while there is a roughly linear price trend across all types of cisterns, it is most pronounced within individual cistern types, e.g. above ground plastic, below-ground plastic, steel, etc. The data in the figure are for above-ground plastic cisterns.

222

Fernandes et al. (2015). The fixed cost function takes the following form

$$
G_{f}=q V \cdot \Theta(V)
$$

where $q\left[\frac{\$}{m^{3}}\right]$ is the unit cost per storage capacity and as before $\Theta$ is the Heaviside step function (Abramowitz and Stegun, 1972), defined here such that $\Theta(0)=0$, in contrast to the step function found in Equation (3).

\subsection{Distributed Costs}

The distributed cost depends on $r\left[\frac{\$}{m^{3}}\right]$, the unit price of water, which varies between locations and is a function of the expected rate at which water must be supplied by the municipal system, $\left\langle H_{m}\right\rangle=h p_{0}$. As an example, the monthly price per unit of water in Durham, NC increases in steps (Figure 4), as is typical of municipalities in the US. Under such a stepped monthly pricing scheme, the unit cost of water can be written as

$$
r=\frac{1}{30 h p_{0}} \sum_{n=1}^{n=k} r_{n}\left(v_{n}-v_{n-1}\right),
$$




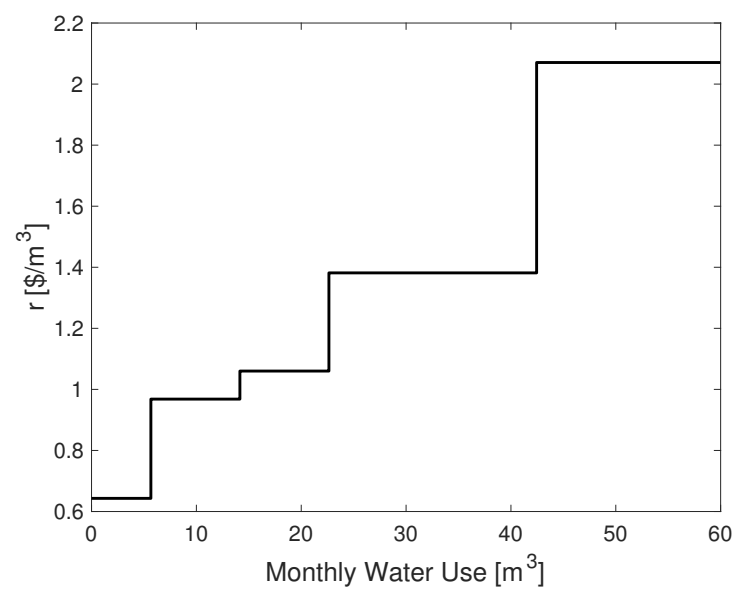

Figure 4: The unit monthly cost per $\mathrm{m}^{3}$ of municipally-supplied water in Durham, NC, USA (www.durhamnc.gov). The price increases occur up to $15 \operatorname{ccf}\left(43 \mathrm{~m}^{3}\right)$ and are thereafter constant, although the plot is only shown up to $21 \mathrm{ccf}\left(60 \mathrm{~m}^{3}\right)$. Once a new increment is reached, the unit price applies only to that increment and not to the entire volume.

where the $r_{n}$ are the monthly unit prices for the $n$th pricing tier, the $v_{n}$ are the monthly volumes at which the $n$th pricing tier ends, and the monthly demand falls into the $k$ th pricing tier, such that $v_{k}=30 h p_{0}$. We also define $T$ as the lifetime of the RWH system in days, and assume that the cistern begins at steady state conditions, so that the transient period to reach steady state can be neglected. The average distributed cost is then the water unit cost multiplied by $\left\langle H_{m}\right\rangle T$, the total expected municipal demand over the lifetime of the cistern

$$
G_{d}=r h T p_{0},
$$

where $p_{0}$ is given by Equations (7) and (9).

\subsection{Solution for the Optimal Cistern Size}

The total cost can be found as the sum of the fixed and distributed costs, $G=G_{f}+G_{d}$. For the cost functions in Equations (14) and (16), an analytical solution for the cistern volume $V$ is obtained by minimizing the total cost. The cost function $G$ is

$$
G=q V \cdot \Theta(V)+r h T p_{0} .
$$


Figure 5 plots the cost functions in Equations (14), (16), and (17) as a function of the cistern volume $V$. The fixed costs (14) always increase with $V$ while the distributed costs (16) always decrease (due to the dependence of $p_{0}$ on $V$ ), yielding a minimum of the cost function $G$. Such a minimum can clearly be seen in Figure 5. We can solve for the optimal cistern volume $V^{*}$ by taking the derivative with respect to $V$ and solving for $V$. The part of this solution containing positive values is expressed below as

$$
\begin{aligned}
& V^{*}=\frac{\alpha \phi A h}{\alpha \phi A \lambda-h} \ln \left\{\frac{h}{\alpha \phi A \lambda}-\frac{h r T}{2 q}\left(1-\frac{h}{\alpha \phi A \lambda}\right)\left(\frac{\alpha \phi A \lambda-h}{\alpha \phi A \lambda}\right)\right. \\
& \left.+\frac{\alpha \phi A \lambda-h}{2 \alpha^{2} \phi^{2} A^{2} \lambda q} \sqrt{4 \alpha \phi A h q r T+[r T(\alpha \phi A \lambda-h)]^{2}}\right\}
\end{aligned}
$$

when $V^{*} \geq 0$ and 0 otherwise. We note that the only $r$-value from Equation (15) which in appears in the solution for $V^{*}$ is the one corresponding to the tier under which the monthly demand falls, so we have termed this value as simply ' $r$ ' with no subscript in Equation (18) and below in Equation (19). We also note that the volume given by Equation $\sqrt{18}$ is negative for rainfall event inter-arrival frequencies below a critical value $\lambda_{c}=\frac{q}{r T}$. For such frequencies the incremental cost per unit volume of the cistern (i.e. the derivative $\frac{d G}{d V}$ ) does not yield a minimum of $G$ for any positive values of $V$, and therefore a RWH system is not financially viable over the time period $T$ and the optimal volume is then equal to 0 . For the special case of $D_{c}=1$ (see Equation (9)),

$$
V^{*}=\sqrt{\frac{\alpha \phi A r h T}{q}}-\alpha \phi A .
$$

It is interesting to observe how the optimal cistern size changes according to the two climate parameters $\alpha$ and $\lambda$. Figure 6 shows the variation in optimal cistern size as a function of $\alpha$ and $\lambda$ (keeping the roof area and household demand from Table 2). For frequent but relatively small events, a larger volume is optimal (the upper left), as even though the events are small they are numerous enough to keep a larger cistern full and thereby offset its cost. A larger cistern volume is also optimal for infrequent but large events (the lower right), as here the additional volume allows for the system to take advantage of the large size of the events and store the resulting rainfall during the longer dry periods. 


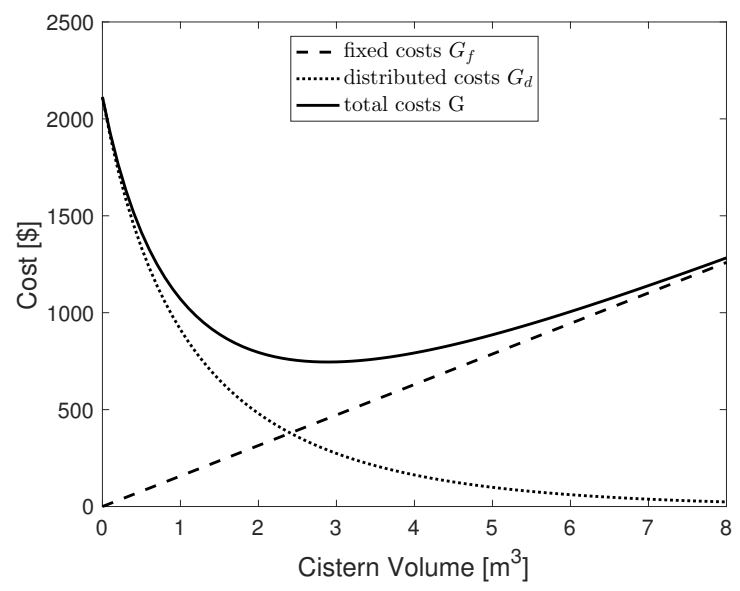

Figure 5: The fixed cistern costs (dashed line) increase linearly with increasing capacity, while the distributed costs (dotted line) of tapping into the municipal supply decrease. The minimum of the total cost (solid line) is taken as the optimal cistern volume.

The inset of Figure 6 (with $\lambda=0.31 \mathrm{~d}^{-1}$ and $\alpha=8.2 \mathrm{~mm}$ ) shows cross-sections of this plot at the $\alpha$ and $\lambda$ values corresponding to Durham, NC. A ridge of relatively large optimal cistern volumes peaks approximately where $D_{c}=1$ (the solid white line in Figure 6). The optimal cistern values are a maximum near this line because there the system is neither on the water-limited RHS of the partitioning diagram (there is exactly enough supply to meet the demand) nor is it in the storage-limited region on the LHS.

\subsection{Expected financial gain and maximum loss}

As a consequence of the steady state condition, if an extreme climate event such as a drought were to occur during the time period $T$ the total cost would not be as predicted in Equation (17). To quantify the financial impact of such an event, both the expected financial benefit from building the cistern and the maximum amount of money that can be lost on the investment can be determined. The expected financial benefit may be quantified as the cost of the cistern subtracted from the cost of obtaining the expected water demand from 




Figure 6: The optimal cistern size as a function of the climate parameters $\alpha$ and $\lambda$. The cross sections of the optimal cistern volume solution, A-A and B-B, are taken at constant $\lambda$ and $\alpha$ values corresponding to Durham, NC. The peak cistern values for a particular $\alpha$ or $\lambda$ value occur near the solid white line, which denotes the section of the parameter space where the cistern demand index $D_{c}=1$.

municipal sources

$$
\langle B\rangle=r\langle H\rangle T-G\left(V^{*}\right)=r h T\left(1-p_{0}\right)-q V^{*} .
$$

The maximum loss, $L_{\max }$, which corresponds to the extreme case of no rainfall collected at all during the lifetime of the cistern, is calculated as the cost of building the cistern added to the cost of obtaining the total water demand from municipal sources

$$
L_{\max }=q V^{*}+r h T \text {. }
$$

The values $\langle B\rangle$ and $L_{\max }$ could help decision-makers by providing information about the financial risk and potential benefit of investing in a RWH system.

\subsection{Optimal size including runoff reduction}

It should also be noted that in addition to its ability to reduce reliance on municipal supplies, rainwater harvesting may provide another important benefit, namely the reduction of runoff. This is true from an environmental as well as a cost standpoint, although in this analysis, we consider water supply to be 
the primary benefit of RWH, with reduced runoff as a potential supplemental benefit. Many municipalities (including Durham, NC) assess a storm water fee which may be (partially or wholly) based on the amount of impervious surface on a property (Wang and Zimmerman, 2015). A RWH system effectively removes a portion of the roof area from the total impervious area of a property, and as the roof area may comprise a sizable fraction of the total land area for some properties (especially in urban settings), it could provide a financial benefit to homeowners via a reduction in storm water fees. This assumes, of course, that municipalities would be willing to consider the installation of a RWH system when assessing such fees. From the partitioning in Equation (10), an expression for the ratio of the rate of expected losses from overflow to the rate of the amount of rainfall captured can also be obtained

$$
\frac{\langle Q\rangle}{\phi A\langle R\rangle}=1-D_{c}\left(1-p_{0}\right) \text {. }
$$

In the absence of a RWH system, all of the rainwater falling on the impervious roof surface, occurring at an average rate $\phi A\langle R\rangle$, becomes runoff. As such, Equation 22 can also be interpreted as the ratio of the runoff rates after and before the installation of a RWH system. If this fraction is multiplied by the roof area $A$, an adjusted roof area is obtained, which could then be used in place of the true roof area when measuring the impervious surface area of a property.

We note that while we have provided an expression for $V^{*}$ which is useful for determining an optimal cistern volume, local governing bodies may have additional requirements and guidelines which must be complied with in the design of a RWH system. For example, the North Carolina Department of Environmental Quality requires property owners who wish to earn runoff reduction credits to design according to specific requirements, including that the system can handle a 10 year, 24-hour storm event, among others (NCDENR, 2014). Other types of regulations, such as local plumbing codes, must also be followed.

Properties are normally divided into different billing tiers based on the amount of impervious area on the property, and then charged a corresponding stormwater fee. This component of the cost function has not been explicitly 
included in the preceding cost analysis for two reasons. First, it is not typical for municipalities to offer a reduction in the stormwater fee in exchange for installing a RWH system, though it is certainly possible. Second, the tiered pricing structure does not qualitatively alter the previous results. As noted by Steffen et al. (2013), Sample and Liu (2014), and Walsh et al. (2014), an additional challenge is that RWH systems must be operated differently depending on whether the goal of the system is providing a water supply or storm water management (or some combination of these), requiring an operator to decide how to balance the two. Nevertheless, the ability of a RWH system to reduce runoff is worth considering for both its environmental and cost-saving benefits.

\section{Conclusions}

An analytically tractable means of representing the water balance in the storage tank of a RWH system has been developed and used to find the expected volume of additional water which would need to be supplied from a municipal source. When combined with the unit cost of water and an estimate of the cost of building a cistern, an expression for the total cost of the RWH system as a function of the cistern tank volume was obtained. A solution was found for this volume, allowing for a direct calculation of the desired storage volume in terms of the roof area, water demand rate, rainfall parameters, and cistern and unit water costs, making clear the role each parameter plays in the optimization. The mathematical models upon which this solution is based have been widely applied to hydrological problems (e.g. in Rodríguez-Iturbe and Porporato (2004)), and we have included a cost function so that optimization is based on more than reliability alone. This is a necessary consideration, as most property owners interested in installing a RWH system will be be concerned with its cost-saving potential as well as its reliability.

By partitioning the water into that which is consumed by the demand and that which is lost to overflow and comparing it to the prior runoff, the potential runoff reduction provided by the system can be found. As many municipalities 
in the US assess a stormwater fee, this represents another potential component of the cost function that could be incorporated, if municipalities are willing to incentivize the installation of a RWH system. The link to climate parameters also allows for the expansion of this work to compare the performance of RWH systems across different regions. Finally, including the various costs associated with a RWH system as part of this optimization could assist in the reduction of municipal water use and/or stormwater runoff. Government planners and water managers could use this information to provide incentives for owners to install RWH systems via subsidies or changes in the price structure of municipal water.

\section{Acknowledgements}

We acknowledge the financial support from National Science Foundation (DGE-1068871, NSF-EAR-0838301, NSF-EAR-1331846, and NSF-EAR-1316258) and Duke Wireless Intelligent Sensor Networks (WISeNet) Integrative Graduate Education and Research Training (IGERT) program, and by the US Department of Defense through the NDSEG Fellowship program.

\section{Appendix}

\subsection{Chapman-Kolmogorov and derivation of steady-state PDF}

The Chapman-Kolmogorov forward equation for the probability of the normalized variable $c$ is (Cox and Miller, 1977)

$$
\frac{\partial}{\partial t} p(c, t)=\frac{\partial}{\partial c}[p(c, t) \rho(c)]-\lambda p(c, t)+\lambda \int_{0}^{c} p(u, t) f_{Y}(c-u, u) d u+\lambda p_{0}(t) f_{Y}(c, 0) .
$$

376 The atom equation is

$$
\frac{d}{d t} p_{0}(t)=-\lambda p_{0}(t)+\rho(0) p_{0}(0, t)
$$

37 The loss function $\rho$ is constant and equal to the constant water demand rate $h$ normalized by dividing by $V$. Note that $f_{Y}(y, s)=\gamma e^{-\gamma y}+\delta(y-1+$ c) $\int_{1-c}^{\infty} \gamma e^{-\gamma u} d u$.

The steady state solutions are given in Equations $(6)$ and (7). 

$383 \quad \xi$ is

$$
\bar{T}(\xi)=\frac{D_{c}}{\lambda D_{c}-1} e^{\xi\left(D_{c} \gamma-\gamma\right)}-\frac{1}{\lambda D_{c}-1} .
$$

384 For the case of $\xi=0$, this reduces to

$$
\bar{T}(0)=\frac{1}{\lambda} .
$$
The frequency of downcrossings (or upcrossings) is

$$
\nu(\xi)=\lambda p_{0} e^{\xi\left(D_{c} \gamma-\gamma\right)},
$$

which reduces to $\nu(0)=\lambda p_{0}$ if the threshold $\xi$ is equal to 0 . The expected number of occurrences of an empty cistern over a given period of time $T$ is therefore $\lambda p_{0} T$. A detailed derivation of the preceding equations can be found in Rodríguez-Iturbe and Porporato (2004).

\section{References}

Abdulla FA, Al-Shareef A. Roof rainwater harvesting systems for household water supply in jordan. Desalination 2009; 243(1):195-207.

Abramowitz M, Stegun IA. Handbook of mathematical functions. ninth printing. 1972.

Assayed A, Hatokay Z, Al-Zoubi R, Azzam S, Qbailat M, Al-Ulayyan A, Bushnaq S, Maroni R, et al. On-site rainwater harvesting to achieve household water security among rural and peri-urban communities in jordan. Resources, Conservation and Recycling 2013; 73:72-7.

Ball T. Harvesting rainwater for domestic uses: an information guide. Reference number/codeGEHO0108BNPN-EE Environmental Agency, Bristol 2001;:248. 
Basinger M, Montalto F, Lall U. A rainwater harvesting system reliability model based on nonparametric stochastic rainfall generator. Journal of Hydrology 2010; 392(3):105-18.

Bocanegra-Martínez A, Ponce-Ortega JM, Nápoles-Rivera F, Serna-González M, Castro-Montoya AJ, El-Halwagi MM. Optimal design of rainwater collecting systems for domestic use into a residential development. Resources, Conservation and Recycling 2014;84:44-56.

Budyko M. Climate and life, 508 pp. Academic, San Diego, Calif 1974;:72-191.

Campisano A, Modica C. Optimal sizing of storage tanks for domestic rainwater harvesting in sicily. Resources, Conservation and Recycling 2012;63:9-16.

Cowden JR, Watkins DW, Mihelcic JR. Stochastic rainfall modeling in west africa: parsimonious approaches for domestic rainwater harvesting assessment. Journal of Hydrology 2008; 361(1):64-77.

Cox DR, Miller HD. The theory of stochastic processes. volume 134. CRC Press, 1977.

Daly E, Porporato A. Impact of hydroclimatic fluctuations on the soil water balance. Water resources research 2006; 42(6).

DeBusk K, Hunt W, Wright J. Characterizing rainwater harvesting performance and demonstrating stormwater management benefits in the humid southeast usa. JAWRA Journal of the American Water Resources Association 2013; 49(6):1398-411.

Easterling DR, Meehl GA, Parmesan C, Changnon SA, Karl TR, Mearns LO. Climate extremes: observations, modeling, and impacts. science 2000; 289(5487):2068-74.

Farreny R, Morales-Pinzón T, Guisasola A, Taya C, Rieradevall J, Gabarrell X. Roof selection for rainwater harvesting: quantity and quality assessments in spain. Water Research 2011;45(10):3245-54. 
Fassman-Beck E, Hunt W, Berghage R, Carpenter D, Kurtz T, Stovin V, Wadzuk B. Curve number and runoff coefficients for extensive living roofs. Journal of Hydrologic Engineering 2015;21(3):04015073.

Feng X, Porporato A, Rodriguez-Iturbe I. Changes in rainfall seasonality in the tropics. Nature Climate Change 2013; 3(9):811-5.

Fernandes LFS, Terêncio DP, Pacheco FA. Rainwater harvesting systems for low demanding applications. Science of The Total Environment 2015;529:91100.

García-Montoya M, Bocanegra-Martínez A, Nápoles-Rivera F, Serna-González M, Ponce-Ortega JM, El-Halwagi MM. Simultaneous design of water reusing and rainwater harvesting systems in a residential complex. Computers \& Chemical Engineering 2015;76:104-16.

Ghisi E, Bressan DL, Martini M. Rainwater tank capacity and potential for potable water savings by using rainwater in the residential sector of southeastern brazil. Building and Environment 2007; 42(4):1654-66.

Guo Y, Baetz BW. Sizing of rainwater storage units for green building applications. Journal of Hydrologic Engineering 2007;.

Hanson L, Vogel R. Generalized storage-reliability-yield relationships for rainwater harvesting systems. Environmental Research Letters 2014;9(7):075007.

Jones MP, Hunt WF. Rainwater harvesting: Guidance for homeowners, 2008.

Jones MP, Hunt WF. Performance of rainwater harvesting systems in the southeastern united states. Resources, Conservation and Recycling 2010; 54(10):623-9.

Khastagir A, Jayasuriya N. Optimal sizing of rain water tanks for domestic water conservation. Journal of Hydrology 2010; 381(3):181-8. 
Krishna HJ, Brown C, Gerston J, Colley S. The texas manual on rainwater harvesting. Texas Water Development Board, 3rd Edition, Austin, Texas, United States of America 2005;

Lee KT, Lee CD, Yang MS, Yu CC. Soil and water: probabilistic design of storage capacity for rainwater cistern systems. Journal of agricultural engineering research $2000 ; 77(3): 343-8$.

Liaw CH, Tsai YL. Optimum storage volume of rooftop rain water harvesting systems for domestic use1. 2004.

Logan JD. Applied mathematics. John Wiley \& Sons, 2013.

Mehrabadi MHR, Saghafian B, Fashi FH. Assessment of residential rainwater harvesting efficiency for meeting non-potable water demands in three climate conditions. Resources, Conservation and Recycling 2013; 73:86-93.

Milly P. An analytic solution of the stochastic storage problem applicable to soil water. Water Resources Research 1993; 29(11):3755-8.

NCDENR . Stormwater best management practices manual. North Carolina Department of Environment and Natural Resources, Raleigh, NC, 2014.

Okoye CO, Solyalı O, Akıntuğ B. Optimal sizing of storage tanks in domestic rainwater harvesting systems: A linear programming approach. Resources, Conservation and Recycling 2015;104:131-40.

Palla A, Gnecco I, Lanza L. Non-dimensional design parameters and performance assessment of rainwater harvesting systems. Journal of Hydrology $2011 ; 401(1): 65-76$.

Palla A, Gnecco I, Lanza L, La Barbera P. Performance analysis of domestic rainwater harvesting systems under various european climate zones. Resources, Conservation and Recycling 2012; 62:71-80.

Pandey DN, Gupta AK, Anderson DM, et al. Rainwater harvesting as an adaptation to climate change. Current science 2003; 85(1):46-59. 
Porporato A, Daly E, Rodriguez-Iturbe I. Soil water balance and ecosystem response to climate change. The American Naturalist 2004; 164(5):625-32.

Porporato A, D’Odorico P, Laio F, Ridolfi L, Rodriguez-Iturbe I. Ecohydrology of water-controlled ecosystems. Advances in Water Resources $2002 ; 25(8): 1335-48$.

Rodríguez-Iturbe I, Porporato A. Ecohydrology of water-controlled ecosystems: soil moisture and plant dynamics. Cambridge University Press, 2004.

Rostad N, Foti R, Montalto FA. Harvesting rooftop runoff to flush toilets: Drawing conclusions from four major us cities. Resources, Conservation and Recycling 2016;108:97-106.

Sample DJ, Liu J. Optimizing rainwater harvesting systems for the dual purposes of water supply and runoff capture. Journal of Cleaner Production 2014;75:174-94.

Steffen J, Jensen M, Pomeroy CA, Burian SJ. Water supply and stormwater management benefits of residential rainwater harvesting in us cities. JAWRA Journal of the American Water Resources Association 2013; 49(4):810-24.

Walsh TC, Pomeroy CA, Burian SJ. Hydrologic modeling analysis of a passive, residential rainwater harvesting program in an urbanized, semi-arid watershed. Journal of Hydrology 2014;508:240-53.

Wang R, Zimmerman JB. Economic and environmental assessment of office building rainwater harvesting systems in various us cities. Environmental science \& technology 2015; 49(3):1768-78. 